\title{
The remittance behaviour of Kenyan sibling migrants
}

Farai Jena

Correspondence: f.jena@sussex.ac.uk Department of Economics, School of Business, Management and Economics, University of Sussex, Jubilee Building, Brighton BN1 9SL, UK

\begin{abstract}
This paper examines the remittance behaviour of multiple-sibling migrants and the motivations of Kenyan siblings in sending remittances to their household of origin. The presence of other siblings is found to decrease the probability of remitting but has no effect on the amount sent. The volume of remittances sent by other siblings is also found to have no statistically significant effect on the amount sent by a sibling. Thus, the evidence obtained offers some mild, though not unambiguous, support for sibling remittances being driven by altruistic as well as independent motives.
\end{abstract}

JEL Classification: B21, D19, J69

Keywords: Siblings, Remittance behaviour, Kenya

\section{Introduction}

Migration in Kenya is characterized by both internal and external movements. External migration mainly consists of cross-border flows within the East-African sub-region and movements to countries in the OECD region largely driven by the search for economic and educational opportunities (Black and King 2004; Clemens 2007; Kanyangoga 2010). World Bank statistics indicate that in 2010, the UK, Tanzania, the USA, Uganda, Canada, Australia, Germany, India, the Netherlands, and Switzerland were the top ten destination countries for Kenyan migrants (World Bank 2011). And, according to OECD migration statistics, the majority of Kenyans residing abroad are men and women between the ages of 25 and 64 with relatively high human capital levels.

The most prevalent type of internal migration in Kenya is rural-to-urban migration for the purpose of obtaining non-agricultural employment in the urban sector (Agesa and Kim 2001). This type of migration is generally perpetuated by regional economic disparities, and migrants tend to be younger and more educated than rural-to-rural migrants (NCPD 2011). Since the current demographic profile in Kenya reflects a younger and better educated population, the ongoing scale of rural-to-urban migration is projected to continue (Black and King op. cit.).

Remittances by migrants are an important component of household income in Kenya. The income levels of family members are often maintained by migrant remittances which serve to maximize the utility of the nuclear family as a group (Knowles and Anker 1981; Mukras et al. 1985). Factors that motivate the sending of remittances by migrants include the need to assist parents in old age, financing the education of

(c) 2016 Jena. Open Access This article is distributed under the terms of the Creative Commons Attribution 4.0 International License (http://creativecommons.org/licenses/by/4.0/), which permits unrestricted use, distribution, and reproduction in any medium, provided you give appropriate credit to the original author(s) and the source, provide a link to the Creative Commons license, and indicate if changes were made. 
younger siblings, inheritance motives, and cultural norms and expectations, among other things.

A 2006 World Bank report estimates that remittances reduced the number of people living in absolute poverty in Kenya by about 2 \% (World Bank 2006). External remittances are reported to be the fourth largest source of foreign currency for Kenya after revenue from tea, horticulture, and tourism (Bett 2013). World Bank estimates suggest that Kenya was the third largest recipient of remittances in Sub-Saharan Africa in 2010 after Nigeria and Sudan. Kenya was also among the top ten remittance recipient countries in terms of its percentage of GDP, with remittances representing $5.4 \%$ of this official measure of economic activity. Internal remittances have also attracted attention in Kenya in recent years with the introduction of the M-PESA mobile money service in 2007 (Jack and Suri 2011; Mas and Radcliffe 2011).

Despite the increasingly prominent role of remittances in Kenya, there remain gaps in the understanding of the factors that drive remittance flows. This lacuna in the literature merits empirical research in order to enhance the understanding of how migrants behave when remitting to their households of origin. In particular, the empirical analysis reported here examines how Kenyan multiple-sibling migrants interact when remitting to their household of origin in order to determine the dominant drivers of their remittance behaviour. Firstly, we investigate whether remitting behaviour differs according to whether the migrant is a sole ${ }^{1}$ - or multiple $^{2}$-sibling migrant. Secondly, we investigate how, if at all, the amount of remittances sent by one sibling migrant is related to the volume of remittances sent by another. The findings reveal that multiple (compared to sole)-sibling migrants are less likely to send remittances. However, the amount of remittances sent by other sibling migrants is found to have no statistically significant effect on the volume of remittances sent by another migrant from the household. The evidence thus provides some support for altruistic and independent motives as potential determinants of sibling remittances.

The structure of the paper is now outlined. Section 2 provides a review of the relevant literature and key theories germane to the current study. Section 3 discusses the data and provides summary statistics for the main variables used in the analysis. The empirical methodology is articulated in Section 4. Section 5 presents and discusses the empirical findings. Finally, Section 6 provides a summary of the main findings and some concluding remarks.

\section{Literature review}

The economic literature on migration has been heavily influenced by Lucas and Stark (1985) and their new economics of labour migration theory where remittances are motivated by pure altruism, pure self-interest, or tempered altruism/enlightened selfinterest. In the empirical literature, studies that have obtained an inverse relationship between the remittances sent and the number of migrants from the same origin household provide support for altruistic motives driving the remittance behaviour of multiple migrants (e.g. Agarwal and Horowitz 2002; Funkhouser 1995). Studies such as Cox (1987), Cox and Rank (1992), and Cox et al. (1998) have found positive relationships between transfer amounts and recipient incomes, thus supporting self-interested inheritance motives. Lucas and Stark (1985), Rosenzweig and Stark (1989), Cox et al. (1998), 
and Amuedo-Dorantes and Pozo (2006), among other studies, find evidence for coinsurance as expected under tempered altruism/enlightened self-interest motives. A more recent and emerging literature uses experimental methods to investigate motives related to remittance sending (e.g. see Batista et al. 2015; Torero and Viceisza 2015; De Arcangelis et al. 2015; Binzel and Fehr 2013).

The few empirical studies that have analysed the behaviour of multiple migrants in the literature, to the author's knowledge, have done so within different settings to the current one. For example, Piotrowski (2008) examines the remittance behaviour of siblings in Thailand using data from rural households. Naufal (2008) examines a sample of Nicaraguan migrants belonging to the same household and finds the decisions to remit are positively correlated across migrant unobservables. For the Dominican Sierra, De la Brière et al. (2002) test whether remittances to parents are motivated by an insurance contract between parents and their migrant children or an investment in future bequests. Agarwal and Horowitz (2002) examine the effect of multiple migrants on the level of remittances in Guyana anticipating the presence of other remitting migrants to reduce the average size of remittances if motivated by altruism. Using US data, Bernheim et al. (1985) examine whether bequests are used to influence the behaviour of potential beneficiaries.

In a study that more closely resembles the current one, Antman (2012) examines the financial contributions of siblings to their families of origin for the case of Mexico. The results reveal that an increase in sibling financial contributions to their parents leads to an increase in the financial contribution of the individual sibling migrant. However, only a few studies have investigated remittance motives for the case of Kenya. For example, Hoddinott $(1992,1994)$ finds evidence that in western Kenya, parents can use inheritable assets to influence the level of assistance that they receive from their sons.

Overall, the literature reveals that the remittance behaviour of sibling migrants is a relatively under-researched topic in the literature, especially in the Kenyan context. The current paper contributes to the literature by employing a relatively recent dataset that was specifically designed to capture migration and remittance flows. To the author's knowledge, the empirical studies that have analysed the behaviour of multiple-sibling migrants in the existing literature have done so for different contexts than the current one. Moreover, the few studies in the literature that have analysed remittance motives for Kenya have used relatively older datasets (e.g. Hoddinott 1992, 1994; Knowles and Anker 1981). Thus, the current analysis potentially contributes more contemporary insights into the understanding of Kenyan migrant remitting behaviour.

\section{Data and summary statistics}

The data used in this paper are obtained from the 2009 Migration and Remittances Household Survey in Kenya and were collected between October and December 2009. The survey is single-round and cross-sectional, capturing information about households with internal, external, and no migrants. It was conducted as part of the Africa Migration Project, which was jointly undertaken by the African Development Bank and the World Bank to improve understanding of migration and remittances in Sub-Saharan Africa.

A two-stage sampling procedure was employed to collect the data. The 1999 Kenya Housing and Population Census was used to map survey areas. In addition, to account 
for population growth and migration, as well as changes in administrative units that had occurred since the 1999 census, the 2005 Kenya Integrated Budget Survey, the 2006 Financial Services Deepening Survey, and the locations of remittance service providers were also used in designing the sampling frame. Plaza et al. (2011) provide a detailed description of the sampling frame and the survey design.

A major challenge was to ensure that households with external migrants were adequately captured. Officers from the Kenya National Bureau of Statistics, village elders, and administrative officers were consulted to help map out clusters with higher concentrations of external migrants resulting in 17 districts in the eight provinces of Kenya, and 92 clusters in these districts, being selected. Thus, the survey is not nationally representative as households with migrants were over-sampled. The final selection of households to interview entailed relisting households in each cluster to identify external, internal, and non-migrant households. Each of these three groups of households was treated as an independent sub-frame, and random sampling was then used to select households within each group.

A total of 1942 households were surveyed. The main respondent to the survey was the head of the household or a representative deputed by the head. Of the households that were surveyed, $49 \%$ were urban based and $51 \%$ rural. At the individual level, information was obtained on a total of 8343 non-migrants and 2245 migrants whose information was reported by the household head.

Due to the emphasis on multiple-sibling migration, we conduct the analysis on sibling migrants belonging to households with more than one child of the household head. We also restrict the sample to migrants who are more than 15 years old. This is because from this age onwards, we expect most migrants to be in a position to send remittances home independently, if they wish. The final sample of usable observations consists of 1092 sibling migrants who are children of the household head in the 647 households within the sample containing at least two siblings.

The first dependent variable used in the preliminary analysis is a dummy variable measuring whether or not a migrant remitted to the household of origin. The second is the volume of remittances which refers to the value of both cash and in-kind remittances sent to the household in the 12 months prior to November/December 2009, valued in Kenyan shillings (Ksh). ${ }^{3}$

The explanatory variables are motivated by the literature on migrant remittances and are also constrained by the nature of the information available in our dataset. Variables measuring the education level at the time of migration, the age, the current employment status, the living situation at the destination, and the length of residence in the destination are constructed. The other migrant-specific explanatory variables include the gender, marital status, birth rank, and location (i.e. internal or external) of the migrant. In addition, a variable measuring the receipt of any monetary transfers from the household of origin in the previous 12 months is also included in the analysis.

Variables that are specific to the household of origin include those capturing the gender, age, education level, and employment status of the household head. The following household demographic variables are also constructed: the proportion of elderly people (that is, members who are more than 59 years old), the proportion of children (that is, members who are less than 7 years old), and the total number of members currently living in the household. A dummy variable for whether or not the household owns land 
and/or a house is also constructed. In addition, a variable measuring whether or not a non-sibling migrant is present in the household is also included in the analysis. Lastly, a set of regional dummy variables are also constructed for the regions of Nairobi, Central, Eastern, North-Eastern, Coast, Rift Valley, Nyanza, and Western.

Table 1 provides summary statistics for the key variables. The table reveals that the average amount of cash and/or in-kind remittances sent is about 30,000 shillings. This equates to an average proportion of remittances as a share of total household expenditure of about $10 \%$. The average remittances sent are about 60,000 shillings for the sample of positive remitters. For this sample, the average proportion of remittances as a share of total household expenditure is about $21 \%$. Thus, remittances represent quite sizable average proportions of the household expenditure budgets.

The table also reveals that there is no statistically significant difference in the mean value of remittances sent by sole- versus multiple-sibling migrants. In the 12 months prior to November/December 2009, about half of migrants sent cash and/or in-kind remittances to the household. Summary statistics for the remaining explanatory variables discussed above are reported in table 5 of the Appendix.

Table 2 provides summary statistics for the key outcome variables used in the analysis focusing on multiple-sibling migrants only (see table 6 in the Appendix for summary statistics for all other explanatory variables). Note that the sample size is smaller here due to restricting the analysis to multiple migrants and has only 700 siblings.

\section{Empirical methodology}

Three econometric methodologies are dominant in the literature modelling the determinants of the amount of migrant remittances: ordinary least squares (OLS) (e.g. see Johnson and Whitelaw 1974; Knowles and Anker 1981), Heckman two-step procedures (e.g. see Hoddinott 1994; Brown and Connell 2006; Liu and Reilly 2004), and censored tobit models (e.g. see Brown 1997; Markova and Reilly 2007). A shortcoming associated with the OLS model is that it does not account for zero remittance observations, which truncates the equation error term and leads to biased and inconsistent estimates if the scale of censorship is sizeable. The popular tobit models address this censorship by assuming that there is only one remittance decision in which the decisions of whether and how much to remit occur simultaneously. However, the imposition of a sign constraint on the probability and level effect is a strong empirical assumption within this regression model. ${ }^{4}$

Table 1 Select summary statistics for sole- and multiple-sibling migrants

\begin{tabular}{|c|c|c|c|c|c|}
\hline Variables & $\begin{array}{l}\text { All sibling } \\
\text { migrants }\end{array}$ & $\begin{array}{l}\text { Sole migrants } \\
\text { only }\end{array}$ & $\begin{array}{l}\text { Multiple migrants } \\
\text { only }\end{array}$ & $\begin{array}{l}t \text { test } / z- \\
\text { score }\end{array}$ & $\begin{array}{l}\text { Positive remitters } \\
\text { only }\end{array}$ \\
\hline $\begin{array}{l}\text { Value of cash and in-kind } \\
\text { remittances (Ksh) }\end{array}$ & $29,751(93,906)$ & $\begin{array}{l}35,876 \\
(101,257)\end{array}$ & $27,866(91,507)$ & 1.20 & $59,942(126,375)$ \\
\hline $\begin{array}{l}=1 \text { if remitted } \\
\text { cash/in-kind; }=0 \\
\text { otherwise }\end{array}$ & $0.5(0.5)$ & $0.54(0.5)$ & $0.48(0.5)$ & $1.78^{*}$ & \\
\hline$N$ & 1092 & 257 & 835 & & 542 \\
\hline
\end{tabular}

Notes to the table: (i) The fifth column reports $t$ test/z-scores for tests for mean/proportion differences between sole- and multiple-sibling migrants, and the sixth column reports summary statistics for positive remitters. (ii) Standard deviations are reported in parentheses. (iii) *represents the statistical significance of the difference for the $10 \%$ significance level 
Table 2 Select summary statistics for multiple-sibling migrants

\begin{tabular}{lllll}
\hline Variables & All multiple-sibling migrants & Remitters only & Non-remitters only & $t$ test \\
\hline $\begin{array}{l}\text { Value of cash and in-kind } \\
\text { remittances (Ksh) }\end{array}$ & $35,950(165,265)$ & $72,522(229,167)$ & & \\
$\begin{array}{l}\text { Value of cash and in-kind } \\
\text { remittances by other }\end{array}$ & $67,493(216,422)$ & $85,665(250,065)$ & $49,630(175,782)$ & $-2.209^{* *}$ \\
$\begin{array}{l}\text { siblings (Ksh) } \\
N\end{array}$ & 700 & 347 & 353 & \\
\hline
\end{tabular}

Notes to the table: (i) The fifth column contains a $t$ test for the difference in means between non-remitters and remitters. (ii) Standard deviations are reported in parentheses. (iii) **represents the statistical significance of the difference for the $5 \%$ significance level

The Heckman two-step procedure addresses this shortcoming by treating the transfer of remittances as a sequential "two-step" decision and allowing the effect of a given variable on the decision to remit to be different from its effect on the level of remittances (Heckman 1979). The identification of the selection effect is one of the key challenges in using this procedure. This is only achieved if there is (at least) one variable in the selection equation not included in the remittance equation. The identifying variables used in the current analysis are discussed in Section 5 below.

\section{Empirical results}

We first estimate the Heckman selection model for the sample of sole- and multiplesibling migrants. The identifying instruments in the Heckman model are provided by the following variables: (i) a dummy variable for the gender of the origin household head, (ii) a dummy variable capturing whether there is a non-sibling migrant from the same household of origin, (iii) the current size of the household of origin, and (iv) a dummy variable for whether the household of origin is located in an urban or a rural area. All these variables exert an insignificant effect on the level of remittances but are jointly significant in determining the probability of remitting, thus statistically justifying their use as identifying variables in this case. The rationale for using these variables as identifiers in the current application is now briefly discussed.

First, it could be argued that households headed by women are more likely to receive remittances compared to those headed by men because migrants tend to be more altruistic towards female heads (Carling 2008). The act of remitting could be influenced by social pressure if children who send remittances to their mothers are perceived as more caring towards them. However, the amount of remittances sent is likely to be dictated by the need of the recipient and not their gender per se. Second, the presence of nonsibling migrants in the household potentially decreases the probability of remitting as the remitting responsibility is distributed across more individuals. However, the amount of remittances sent is more likely to be determined by how much the migrant is capable of remitting and the needs of the receiving household, not the presence of non-sibling migrants per se. Third, an increase in the size of the household is likely to increase the demand for remittances as migrants may feel obliged to remit to larger households. However, it does not necessarily affect how much is actually remitted as an increase in household size may not directly translate to an increase in the amount of remittances needed. In addition, the capacity of the migrant to remit should affect the level of remittances sent and not the size of the receiving household in itself. Fourth, households located in urban areas generally have higher income levels, can diversify 
their income sources more easily compared to rural households, and so are less likely to demand or require remittances. However, the amount of remittances a migrant sends, if they decide to remit, should not be affected by urban/rural location itself. Overall, and given their statistical relevance, it does not appear implausible to treat these four identifying variables as exogenous with respect to the decision of how much to remit and as independent of the level of remittances.

In the Heckman two-step model, the inverse Mills ratio is found to be statistically insignificant. Thus, on the assumption of adequate instruments, the null hypothesis of no selectivity bias is upheld by the data in this application. This suggests that the selectivity in sibling decisions to remit and the amount of remittances to send has been captured entirely through the inclusion of the observable covariates. Because there is no sample selection in regard to unobservables, the remittance level model can be estimated by uncorrected OLS using the sample of positive remitters (see Wooldridge 2010 pp. 805-6). We thus employ OLS for the level of remittances and a probit model for the probability of remitting as the preferred econometric models. Table 3 reports the estimates obtained. ${ }^{5}$

The empirical estimates reveal that multiple-sibling migrants are about six percentage points less likely to remit, on average and ceteris paribus, relative to sole-sibling migrants. This corresponds to a $12 \%$ decrease in the probability of remitting relative to the mean. ${ }^{6}$ Table 3 also reveals that, conditional on a sibling remitting, the amount of remittances sent by a multiple-sibling migrant is not statistically different from that sent by a sole-sibling migrant. This finding is invariant to whether the model is estimated using different definitions for the remittance metric. ${ }^{7}$

In contrast to Hoddinott $(1992,1994)$, who reports inheritable assets to have a positive effect on the amount of remittances sent for the case of Kenya, our results appear to be inconsistent with self-interested competitive motives as drivers of the remittance behaviour of Kenyan sibling migrants. If siblings are driven by competition, the presence of other sibling migrants should have a positive effect on both the probability and the amount of remittances sent to the household of origin. Additional results supporting the non-prevalence of inheritance motives in our analysis show that the ownership of inheritable assets by the household of origin does not have any significant effect on the remittance behaviour of both multiple- and sole-sibling migrants. ${ }^{8}$

Table $\mathbf{3}$ The probability of remitting and the volume of remittances

\begin{tabular}{lll}
\hline Variables & Probability of remitting & Remittance level \\
\hline$=1$ if multiple-sibling migrant & $-0.058^{*}$ & -8226 \\
& $(0.0339)$ & $(13,558)$ \\
$=1$ if sole-sibling migrant & $-^{+}$ & $-{ }^{\dagger}$ \\
Other control variables included & Yes & Yes \\
$N$ & 1092 & 542 \\
$R$-squared & & 0.235 \\
Pseudo $R$-squared & 0.3243 &
\end{tabular}

Notes to the table: (i) The second column reports the impact effect for the probability of remitting using a probit model based on the full sample of remitting and non-remitting siblings. The dependent variable is equal to 1 if a migrant remitted and 0 otherwise. The third column presents estimates for the remittance volume model based on OLS using the sample of non-zero remitters. Here, the dependent variable is the total amount of cash and in-kind remittances sent to the household measured in Kenyan shillings. (ii) * denotes statistical significance from zero at the $10 \%$ level using a two-tailed test. (iii) Robust standard errors clustered by household are reported in parentheses. (iv) ${ }^{\dagger}$ denotes the base group. (iv) Other variables are included in these models but not shown here in order to conserve space (see text for details) 
The finding that the presence of other sibling migrants has a negative effect on the probability of remitting provides support for altruism (e.g. see Funkhouser 1995; Gubert 2002). However, the insignificance of the presence of other sibling migrants on the amount of remittances sent to the household of origin may be suggestive of an independent self-insurance contract between each sibling migrant and the household of origin (Stark and Lucas 1988). Unfortunately, the absence of variables in the dataset that offer a measure of risk constrains testing co-insurance motives more explicitly. In the literature, Agarwal and Horowitz (2002) use a variable measuring the unemployment rate at the destination as a risk variable assuming it to be positive if the motive is insurance and indeterminate if the motive is altruism. When a variable for the unemployment rate in the destination country is introduced as a measure of risk, a statistically insignificant effect is obtained in the OLS model and a negative significant effect in the probability model. Although this finding is in conflict with the predictions of the co-insurance motive, caution is justified here as the unemployment rate is likely to provide a very crude proxy for risk in the current context.

Overall, the foregoing evidence provides no empirical support for competition. Rather, the evidence provides some support for altruism and self-insurance motives. In a recent paper, Batista and Umblijs (2016) also find evidence consistent with selfinsurance motives among migrant remitters in Ireland. In addition, similar to the current analysis, the aforementioned study finds that bequest motives do not seem to be driving migrant remittances.

However, it may be that other motives besides those found in the traditional remittance literature may better explain the remittance motives of Kenyan siblings. For example, there could be some form of sharing of remitting responsibilities among multiple migrants. That is, the presence of other siblings decreases the remittance burden on any one sibling migrant. This may manifest itself in terms of a negative effect on the probability of remitting for the variable capturing the presence of other siblings. However, if this is the case, the nature of remittance sharing responsibilities is indeterminate given the insignificant effect of the presence of other migrants on the amount of remittances sent. In addition, it is not clear what sign to expect if it is the case that there are shared responsibilities. For example, a negative effect of the presence of other migrants on the amount of remittances sent could imply that multiple siblings each contribute towards meeting the remittance needs of the household such that each migrant assumes a smaller share of the remittances. This would be analogous to the altruistic model which predicts a negative sign for both the probability and the amount of remittances sent. On the other hand, the insignificant sign we obtain here may suggest a strategy where multiple-sibling migrants take turns to meet the remittance needs of the household such that the remitting migrant bears the full share of the remittances. Unfortunately, given the cross-sectional nature of our data, we are unable to determine whether this feature is persistent across time.

We now narrow down the sample to multiple-sibling migrants only. We estimate the effect of the total amount of remittances sent by other siblings belonging to the same household of origin on the amount of remittances sent by a sibling. As in Antman (2012), the rationale in using the total remittances sent by other siblings as the explanatory variable of interest is that siblings are assumed to care about the total remittances received by their parents, as opposed to the average. Due to the exclusive focus on 
multiple-sibling migrants, the sample is smaller than that for the initial analysis now comprising a total of 700 siblings.

Having already determined that the uncorrected OLS model is appropriate for our analysis, a major concern is that its parameters may not be identified because the variable measuring the remittances of other sibling migrants may be endogenous due to a simultaneity bias. That is, the remittances of sibling $i$ are a function of the remittances of other siblings and vice versa. Such simultaneity is referred to by Manski (1993) as a "reflection" problem that arises when the behaviour of an individual affects, and is also affected by, the behaviour of a reference group. It is well known that when explanatory variables are endogenous, OLS yields biased and inconsistent estimates of the causal effect of an explanatory variable on the outcome of interest (Bound et al. 1995). The common strategy for dealing with this endogeneity is instrumental variable (IV) estimation. After some experimentation, we find the following variables to be the most suitable instruments: (i) the total number of other sibling migrants with secondary education and (ii) the total number of other sibling migrants living in an external destination. In the literature, Antman (op. cit.) also uses summations of other sibling characteristics as instruments for the amount of remittances sent by a sibling.

The reasoning behind the use of these variables as identifying instruments now follows. Given that the objective is to measure how responsive the remittances of an individual sibling are to those of other siblings, the decision to remit should not be directly influenced by the characteristics of other siblings but rather by how much other siblings have remitted. For example, other siblings may remit more to the household because they have higher levels of education and/or live in a destination with higher income levels. Or, other siblings may be more educated and/or earn more and yet choose to remit less, if at all. However, the amount of money an individual sibling chooses to remit is not a function of the characteristics of other siblings per se but rather a response to how much the household of origin has received. Thus, it does not matter why other siblings are remitting at the level they are but rather how much they are remitting. The view here is that the actual amount remitted to the household of origin trumps any reason for siblings remitting (Antman op. cit.), hence the assumption that the behaviour of the individual responds to the remittance levels of other siblings and not directly to their characteristics.

However, a counter argument may be that the characteristics of other siblings may affect individual remittances in many other ways besides their direct effect on how much those other siblings remit and thus fail to qualify as valid instruments. For example, a household may strategically invest more in the education of one sibling over another with the expectation that the former sibling will send back remittances to the household upon migrating. If both siblings end up migrating, the remittance behaviour of each sibling may be a direct response to the education levels of the other. For instance, a sibling may remit less because he/she expects siblings with higher education levels, owing to higher levels of investment by the household of origin, to remit more. Thus, the instruments discussed above may be potentially weak. ${ }^{9}$

A set of statistical tests are undertaken to determine the validity of these instruments. The instruments should be relevant in predicting the amount of remittances sent by other siblings (i.e. in the reduced-form equation) but orthogonal to the error term in sibling $i$ 's remittance equation in order to qualify as a valid set of instruments. The null 
hypothesis that the instruments are orthogonal to the error process in the main equation is upheld using both the Sargan $\left(\chi^{2}(1)=0.448\right)$ and Hansen $\left(\chi^{2}(1)=0.194\right)$ tests.

In testing for the relevance of these instruments, we find them to be jointly statistically significant at the $1 \%$ level of significance in the remittance equation for other siblings $(F(2,327)=6.87)$. Because the $F$-value of 6.87 is below the rule of thumb of 10 suggested by Staiger and Stock (1994), and as anticipated in the discussion above, we infer that the instruments are weak and may not be relevant for the task at hand. The null hypothesis of the Wu-Hausman test for the exogeneity of the variable capturing the amount of remittances sent by other siblings is upheld by the data suggesting that the variable is exogenous. However, given these weak instruments, the power of the Wu-Hausman test is acknowledged to be poor, and therefore, we proceed to employ an alternative IV strategy that caters for the weak instruments used. Moreira and Poi (2003) propose a conditional likelihood ratio test that is robust to the use of weak instruments within an IV framework. The test also provides a confidence interval for the parameter for the endogenous variable that is robust to the presence of weak instruments and the exclusion of relevant instruments and furthermore allows valid inference for the parameter of interest (see Moreira and Poi 2003; Mikusheva and Poi 2006). We thus employ this approach in the current analysis.

The results obtained are reported in Table 4. The estimates for the OLS model reveal that a 1 shilling increase in the amount of remittances sent by other siblings increases the remittances sent by a sibling by 30 cents, on average and ceteris paribus. This

Table 4 OLS, IV, and conditional IV regression estimates (multiple-sibling migrants only)

\begin{tabular}{|c|c|c|c|}
\hline Variables & OLS & IV & Conditional IV \\
\hline \multirow[t]{2}{*}{ Amount of remittances sent by other siblings } & $0.295^{* * *}$ & 0.153 & 0.0752 \\
\hline & $(0.0470)$ & $(0.174)$ & $(0.160)$ \\
\hline \multicolumn{3}{|l|}{ Conditional likelihood ratio test confidence interval } & $\begin{array}{l}{[-0.32,0.52]} \\
p \text { value }=0.49\end{array}$ \\
\hline \multicolumn{2}{|l|}{ F-test of instruments } & \multicolumn{2}{|l|}{$F(2,327)=6.87, p$ value $=0.0012$} \\
\hline \multicolumn{2}{|l|}{ Sargan test (assuming homoscedasticity) } & \multicolumn{2}{|l|}{$x^{2}(1)=2.170, p$ value $=0.141$} \\
\hline \multicolumn{2}{|l|}{ Hansen's J-statistic (assuming heteroscedasticity) } & \multicolumn{2}{|l|}{$x^{2}(1)=2.22, p$ value $=0.136$} \\
\hline \multicolumn{2}{|l|}{ Wu-Hausman exogeneity test } & \multicolumn{2}{|l|}{$F(1327)=0.696, p$ value $=0.405$} \\
\hline \multicolumn{4}{|c|}{ Weak instrument robust tests for endogenous variable ${ }^{\top}$} \\
\hline \multicolumn{2}{|l|}{ Conditional likelihood ratio test } & \multicolumn{2}{|l|}{ Stat $()=0.53,$.$p value =0.476$} \\
\hline \multicolumn{2}{|l|}{ Anderson-Rubin test } & \multicolumn{2}{|l|}{$x^{2}(2)=2.71, p$ value $=0.258$} \\
\hline \multicolumn{2}{|l|}{$\begin{array}{l}\text { Lagrange multiplier test for the structural } \\
\text { parameter }\end{array}$} & \multicolumn{2}{|l|}{$x^{2}(1)=0.48, p$ value $=0.487$} \\
\hline \multicolumn{2}{|l|}{$J$ test for over-identification } & \multicolumn{2}{|l|}{$x^{2}(1)=2.22, p$ value $=0.136$} \\
\hline \multicolumn{2}{|l|}{ Wald test ${ }^{F}$} & \multicolumn{2}{|l|}{$x^{2}(1)=0.77, p$ value $=0.38$} \\
\hline Other explanatory variables & Yes & Yes & Yes \\
\hline N & 347 & 347 & 347 \\
\hline$R$-squared & 0.255 & 0.233 & 0.233 \\
\hline
\end{tabular}

Notes to the table: (i) ${ }^{* * *}$ denotes statistical significance from zero at the $1 \%$ level using a two-tailed test. (ii) Robust standard errors clustered at the household level are reported in parentheses. (iii) Other variables are included in these models but not shown here in order to conserve space (see text for details). (iv) The following variables are used as instruments in the IV and conditional IV models: the total number of other sibling migrants with secondary education and the total number of other sibling migrants residing in an external destination. (v) ${ }^{\dagger}$ These are tests of the significance of the coefficient on the endogenous variable in the IV model which are robust to weak instruments. (vi) $\mathrm{F}$ This is a Wald test of the significance of the coefficient on the endogenous variable in the IV model and is not robust to weak instruments 
estimated effect is consistent with, but larger, than that obtained by Antman (op. cit.) when endogeneity is unaccounted for. ${ }^{10}$ However, both the IV and conditional IV results reveal that after correcting for the endogeneity of the amount of remittances sent by other siblings, there is no statistically significant effect on the remittances sent by a given sibling to the household. The insignificant effect of the amount of remittances sent by other siblings holds for both the IV and conditional IV when we estimate the models separately for cash and in-kind remittances. The results obtained contrast with those of Antman (op. cit.) who reports a positive and statistically significant effect for the financial contributions of other siblings after employing an IV strategy. ${ }^{11}$

Overall, when we treat the remittances of other siblings as exogenous, the total amount of remittances sent by other siblings has a positive and statistically significant effect on the remittances of a sibling. This seems to suggest that the remittances of multiple-sibling migrants are complementary. However, after controlling for the endogeneity of the remittances, we find that the amount of remittances sent by other siblings has no statistically significant effect on sibling remittances. The finding mirrors the results obtained in the earlier analysis reported in this paper. The insensitivity of a sibling's remittances to those sent by other siblings suggests that, in and of themselves, remittances sent by others have no direct effect on the remittances of a sibling. Rather, there seems to be an underlying factor motivating multiple-sibling migrants to remit to the household, other than the amount remitted by other family members. Thus, the remittances of multiple-sibling migrants neither complement nor substitute each other. A potential explanation for this may be that the remittances of siblings are driven by independent motives as predicted in the literature under co-insurance models. However, we cannot preclude other factors. For example, if there is a sharing of remittance responsibilities, the remittance needs of the household may be fully met by particular siblings at any given time, thus yielding the statistically insignificant effect reported here.

We are careful not to draw strong conclusions from our empirical findings. Firstly, given the weak instruments used in the IV model, we remain sceptical about the validity of our estimates even after employing the various tests and methods assumed robust to weak instrumentation. A second caveat is that the information about the remittances sent by siblings was provided by the household head or, in a few cases, his/her deputed representative. Thus, there may be recall error as the respondent may not accurately remember the exact amount of remittances sent by each sibling. Another potential bias resulting from the head being the respondent may arise from, for example, an unwillingness to disclose the fact that some of his/her children may not have been supporting the household as much as he/she would have liked. It could be the case, therefore, that the reported per sibling remittance amounts are biased towards equality. The direction of the OLS bias in Table 4 suggests such measurement error is unlikely. However, the absence of strong instruments demands circumspection in regard to the final set of empirical results reported here.

\section{Conclusions}

The evidence reported in this paper reveals that multiple-sibling migrants are less likely to remit compared to sole-sibling migrants. However, being a multiple-sibling migrant has no effect on the amount of remittances sent if a migrant remits. In addition, when 
we narrow the analysis to multiple-sibling migrants only and treat the remittances sent by other siblings as endogenous, we find that the amount of remittances sent by other siblings exert no statistically significant effect on the remittances sent by the other sibling.

Our empirical findings are in conflict with competitive remittance behaviour among multiple-sibling migrants. This is contrary to most of the existing evidence on the motives of migrant remittances in Kenya (e.g. see Hoddinott 1994). However, our findings do not offer strong support for any one remittance motive with evidence consistent with both altruistic and independent motives obtained. In addition, there could be other motives that are relevant in explaining the remitting behaviour of Kenyan siblings besides those that are to be found in the extant literature. Therefore, the current remittance literature may need to evolve to incorporate other motives that are not fully captured in this literature if a more complete understanding on these motives is to be provided.

\section{Endnotes}

${ }^{1}$ A sole-sibling migrant is an individual who is the only sibling migrant in the household but who belongs to a household that has at least two siblings.

${ }^{2} \mathrm{~A}$ multiple-sibling migrant refers to an individual from a household where at least two children of the household head are migrants.

${ }^{3}$ Four values which appear to be overly extreme are eliminated from the dataset.

${ }^{4}$ A specification test using the likelihood ratio test, based on Lin and Schmidt (1984), yields a test statistic of 372 for this application. This revealed a decisive rejection of the censored tobit model.

${ }^{5}$ The table shows effects for the key variables of interest. The effects for the remaining control variables are presented in table 7 in the Appendix for only those effects that are significant in at least one of the models.

${ }^{6} \mathrm{~A}$ multinomial logit model is also estimated for the following categories of remittances: no remittances, cash only, in-kind only, and both cash and in-kind remittances. A statistically significant negative effect of being a multiple-sibling migrant on the probability of remitting for the cash and in-kind remittance category and an insignificant effect for the cash only and in-kind only categories are obtained.

${ }^{7}$ For instance, the OLS model is also estimated under three specifications with the following dependent variables: (i) the value of cash remittances sent, (ii) the value of in-kind remittances sent, and (iii) the value of both cash and in-kind remittances sent. In all specifications, we obtain an insignificant effect for the multiple-sibling migrant dummy variable.

${ }^{8}$ Additional details on these results are available from the author on request.

${ }^{9}$ The author would like to acknowledge an anonymous referee for providing constructive comments here.

${ }^{10}$ In the study by Antman, a 100 peso increase in siblings' contributions leads to a 12 peso increase in the financial contribution for the individual migrant child when endogeneity is not accounted for.

${ }^{11} \mathrm{~A} 100$ peso increase in siblings' contributions leads to a 6 peso increase in the financial contribution for the individual migrant child when endogeneity is accounted for in the study by Antman. 


\section{Appendix}

Table 5 Detailed summary statistics for sole- and multiple-sibling migrants

\begin{tabular}{|c|c|c|c|c|c|}
\hline Variables & All sibling migrants & Sole migrants only & Multiple migrants only & $t$ test $/ z$-score & Positive remitters only \\
\hline$=1$ if multiple-sibling migrant & $0.76(0.42)$ & & & & $0.74(0.44)$ \\
\hline$=1$ if aged 15 to $25 ;=0$ otherwise & $0.3(0.46)$ & $0.37(0.48)$ & $0.27(0.45)$ & $3.05^{* * *}$ & $0.19(0.39)$ \\
\hline$=1$ if aged 26 to $35 ;=0$ otherwise & $0.45(0.5)$ & $0.42(0.49)$ & $0.46(0.5)$ & -1.13 & $0.53(0.50)$ \\
\hline$=1$ if aged 26 to $45 ;=0$ otherwise & $0.17(0.38)$ & $0.12(0.33)$ & $0.19(0.39)$ & $-2.32^{* *}$ & $0.21(0.41)$ \\
\hline$=1$ if aged $46+;=0$ otherwise & $0.08(0.28)$ & $0.09(0.28)$ & $0.08(0.28)$ & 0.15 & $0.08(0.27)$ \\
\hline \multicolumn{4}{|l|}{$x^{2}$ test for age dummies } & \multicolumn{2}{|l|}{$11.66^{* * *}$} \\
\hline Birth rank & $2.21(1.40)$ & $1.40(0.68)$ & $2.45(1.47)$ & $-15.99^{* * *}$ & $1.94(1.21)$ \\
\hline$=1$ if male; $=0$ otherwise & $0.57(0.5)$ & $0.61(0.49)$ & $0.55(0.5)$ & $1.49^{*}$ & $0.60(0.49)$ \\
\hline$=1$ if university education; $=0$ otherwise & $0.18(0.38)$ & $0.15(0.36)$ & $0.18(0.39)$ & -1.20 & $0.22(0.41)$ \\
\hline$=1$ if secondary education; $=0$ otherwise & $0.63(0.48)$ & $0.61(0.49)$ & $0.64(0.48)$ & -0.61 & $0.62(0.49)$ \\
\hline$=1$ if primary education; $=0$ otherwise & $0.19(0.39)$ & $0.23(0.42)$ & $0.18(0.38)$ & $1.92^{* *}$ & $0.16(0.37)$ \\
\hline \multicolumn{4}{|l|}{$x^{2}$ test for education dummies } & \multicolumn{2}{|l|}{4.27} \\
\hline$=1$ if employed; $=0$ otherwise & $0.6(0.49)$ & $0.54(0.5)$ & $0.62(0.49)$ & $-2.24^{* *}$ & $0.84(0.37)$ \\
\hline$=1$ if self-employed; $=0$ otherwise & $0.1(0.3)$ & $0.09(0.28)$ & $0.1(0.3)$ & -0.76 & $0.10(0.29)$ \\
\hline$=1$ if unemployed $/$ student $;=0$ otherwise & $0.30(0.46)$ & $0.37(0.48)$ & $0.28(0.45)$ & $2.90^{* * *}$ & $0.07(0.25)$ \\
\hline \multicolumn{4}{|l|}{$x^{2}$ test for employment dummies } & \multicolumn{2}{|l|}{$15.73^{* * *}$} \\
\hline$=1$ if married; $=0$ otherwise & $0.46(0.5)$ & $0.39(0.49)$ & $0.48(0.5)$ & $-2.50^{* *}$ & $0.55(0.50)$ \\
\hline$=1$ if lives with spouse and/or children; $=0$ otherwise & $0.39(0.49)$ & $0.3(0.46)$ & $0.42(0.49)$ & $-3.35^{* * *}$ & $0.45(0.50)$ \\
\hline$=1$ if lives with relatives and/or friends; $=0$ otherwise & $0.2(0.4)$ & $0.17(0.37)$ & $0.21(0.41)$ & $-1.44^{*}$ & $0.12(0.32)$ \\
\hline$=1$ if lives alone; $=0$ otherwise & $0.41(0.49)$ & $0.53(0.5)$ & $0.38(0.48)$ & $4.51^{* * *}$ & $0.43(0.50)$ \\
\hline \multicolumn{4}{|l|}{$x^{2}$ test for living situation dummies } & \multicolumn{2}{|l|}{$20.21^{* * *}$} \\
\hline
\end{tabular}


Table 5 Detailed summary statistics for sole- and multiple-sibling migrants (Continued)

\begin{tabular}{|c|c|c|c|c|c|}
\hline Migration length spline 1 & $3.63(1.54)$ & $3.13(1.58)$ & $3.78(1.5)$ & $-6.02^{* * *}$ & $3.88(1.44)$ \\
\hline Migration length spline 2 & $2.76(5.88)$ & $1.25(3.35)$ & $3.22(6.39)$ & $-4.74^{* * *}$ & $2.65(5.09)$ \\
\hline$=1$ receives transfers from the household of origin; $=0$ otherwise & $0.17(038)$ & $0.28(0.45)$ & $0.14(0.34)$ & $5.42^{* * *}$ & $0.06(0.24)$ \\
\hline$=1$ if located in external destination; $=0$ otherwise & $0.39(0.49)$ & $0.49(0.5)$ & $0.35(0.48)$ & $4.08^{* * *}$ & $0.41(0.49)$ \\
\hline$=1$ if head aged 25 to $44 ;=0$ otherwise & $0.08(0.27)$ & $0.15(0.36)$ & $0.06(0.23)$ & $5.02^{* * *}$ & $0.05(0.23)$ \\
\hline$=1$ if head aged 45 to $54 ;=0$ otherwise & $0.25(0.44)$ & $0.36(0.48)$ & $0.22(0.41)$ & $4.60^{* * *}$ & $0.22(0.41)$ \\
\hline$=1$ if head aged 55 to $65 ;=0$ otherwise & $0.29(0.46)$ & $0.25(0.44)$ & $0.31(0.46)$ & $-1.62^{*}$ & $0.31(0.46)$ \\
\hline$=1$ if head aged 66 or more; $=0$ otherwise & $0.37(0.48)$ & $0.23(0.42)$ & $0.42(0.49)$ & $-5.41^{* * *}$ & $0.42(0.49)$ \\
\hline$x^{2}$ test for head age dummies & & & & $57.96^{* * *}$ & \\
\hline$=1$ if head has university education; $=0$ otherwise & $0.1(0.29)$ & $0.1(0.3)$ & $0.09(0.29)$ & 0.127 & $0.07(0.26)$ \\
\hline$=1$ if head has secondary education; $=0$ otherwise & $0.39(0.49)$ & $0.34(0.47)$ & $0.4(0.49)$ & $-1.87^{* *}$ & $0.38(0.49)$ \\
\hline$=1$ if head has primary education; $=0$ otherwise & $0.52(0.5)$ & $0.56(0.5)$ & $0.5(0.5)$ & $1.75^{* *}$ & $0.55(0.50)$ \\
\hline$x^{2}$ test for education dummies & & & & 3.64 & \\
\hline$=1$ if head is employed; $=0$ otherwise & $0.18(0.38)$ & $0.28(0.45)$ & $0.15(0.36)$ & $4.99^{* * *}$ & $0.14(0.35)$ \\
\hline$=1$ if head is self-employed; $=0$ otherwise & $0.38(0.49)$ & $0.42(0.49)$ & $0.37(0.48)$ & 1.2 & $0.41(0.49)$ \\
\hline$=1$ if head is unemployed; $=0$ otherwise & $0.15(0.35)$ & $0.14(0.35)$ & $0.15(0.35)$ & -0.08 & $0.13(0.33)$ \\
\hline$=1$ if head is retired; $=0$ otherwise & $0.29(0.45)$ & $0.16(0.36)$ & $0.33(0.47)$ & $-5.48^{* * *}$ & $0.32(0.47)$ \\
\hline$x^{2}$ test for employment dummies & & & & $41.67^{* * *}$ & \\
\hline Proportion of elderly people & $0.21(0.27)$ & $0.09(0.14)$ & $0.25(0.29)$ & $-8.35^{* * *}$ & $0.22(0.25)$ \\
\hline$=1$ if the household owns land/house; $=0$ otherwise & $0.88(0.32)$ & $0.86(0.34)$ & $0.89(0.31)$ & -1.19 & $0.91(0.28)$ \\
\hline$=1$ if head is male; $=0$ otherwise & $0.69(0.46)$ & $0.65(0.48)$ & $0.7(0.46)$ & $-1.61^{*}$ & $0.67(0.47)$ \\
\hline Proportion of children & $0.06(0.12)$ & $0.08(0.13)$ & $0.06(0.11)$ & $2.15^{* *}$ & $0.07(0.12)$ \\
\hline Household size & $4.48(2.24)$ & $5.22(2.11)$ & $4.25(2.23)$ & $6.18^{* * *}$ & $4.70(2.11)$ \\
\hline
\end{tabular}


Table 5 Detailed summary statistics for sole- and multiple-sibling migrants (Continued)

\begin{tabular}{|c|c|c|c|c|c|}
\hline$=1$ if non-sibling migrant present; $=0$ otherwise & $0.13(0.33)$ & $0.08(0.27)$ & $0.14(0.35)$ & $-2.47^{* *}$ & $0.09(0.28)$ \\
\hline$=1$ if the household in urban location; $=0$ otherwise & $0.42(0.49)$ & $0.47(0.5)$ & $0.4(0.49)$ & $1.80^{* *}$ & $0.35(0.48)$ \\
\hline$N$ & 1092 & 257 & 835 & & 542 \\
\hline
\end{tabular}

Notes to the table: (i) The fifth column reports the $t$ test $/ z$-scores for tests for mean/proportion differences between sole- and multiple-sibling migrants. (ii) Standard deviations are reported in parentheses. (iii) ${ }^{*}{ }^{* *}$, and *** represent the statistical significance of the differences for the 10,5 , and $1 \%$ significance levels, respectively. (iv) The $x^{2}$ tests are testing for differences between sole- and multiple-sibling migrants for categorical variables 
Table 6 Detailed summary statistics for multiple-sibling migrants

\begin{tabular}{|c|c|c|c|c|}
\hline Variables & $\begin{array}{l}\text { All multiple-sibling } \\
\text { migrants }\end{array}$ & Remitters only & $\begin{array}{l}\text { Non-remitters } \\
\text { only }\end{array}$ & $\begin{array}{l}t \text { test } / z- \\
\text { score }\end{array}$ \\
\hline$=1$ if male; $=0$ otherwise & $0.55(0.50)$ & $0.59(0.49)$ & $0.5(0.5)$ & $-2.383^{* * *}$ \\
\hline Age & $30.57(8.40)$ & $32.03(7.63)$ & $29.13(8.87)$ & $-4.639^{* * *}$ \\
\hline Birth rank & $2.38(1.40)$ & $2.09(1.22)$ & $2.67(1.50)$ & $-5.53^{* * *}$ \\
\hline$=1$ if married; $=0$ otherwise & $0.50(0.50)$ & $0.59(0.49)$ & $0.41(0.49)$ & $-4.756^{* *}$ \\
\hline$=1$ if secondary education; $=0$ otherwise & $0.65(0.48)$ & $0.63(0.48)$ & $0.67(0.47)$ & 1.037 \\
\hline$=1$ if university education; $=0$ otherwise & $0.18(0.38)$ & $0.23(0.42)$ & $0.13(0.34)$ & $-3.385^{* * *}$ \\
\hline$=1$ if primary education; $=0$ otherwise & $0.17(0.38)$ & $0.14(0.35)$ & $0.20(0.40)$ & $2.09^{* *}$ \\
\hline$x^{2}$ test for education dummies & & & & $13.27^{* * *}$ \\
\hline$=1$ if lives alone; $=0$ otherwise & $0.39(0.49)$ & $0.43(0.5)$ & $0.35(0.48)$ & $-2.358^{* * *}$ \\
\hline$=1$ if lives with spouse and/or children; $=0$ otherwise & $0.41(0.49)$ & $0.46(0.5)$ & $0.35(0.48)$ & $-2.816^{* * *}$ \\
\hline$=1$ if lives with other relations; $=0$ otherwise & $0.21(0.40)$ & $0.11(0.31)$ & $0.30(0.46)$ & $6.42^{* * *}$ \\
\hline$x^{2}$ test for living situation dummies & & & & $39.02^{* * *}$ \\
\hline Length of migration (years) & $6.75(6.81)$ & $6.94(5.98)$ & $6.57(7.55)$ & -0.713 \\
\hline$=1$ if located in external destination; $=0$ otherwise & $0.37(0.48)$ & $0.4(0.49)$ & $0.35(0.48)$ & $-1.504^{*}$ \\
\hline$=1$ if the head has secondary education; $=0$ otherwise & $0.43(0.49)$ & $0.41(0.49)$ & $0.44(0.5)$ & 0.5685 \\
\hline$=1$ if the head has university education; $=0$ otherwise & $0.10(0.30)$ & $0.09(0.28)$ & $0.12(0.32)$ & $1.416^{* * *}$ \\
\hline$=1$ if the head has primary education; $=0$ otherwise & $0.47(0.50)$ & $0.50(0.50)$ & $0.44(0.50)$ & $-1.43^{*}$ \\
\hline$x^{2}$ test for head education dummies & & & & 3.06 \\
\hline Number of children in the household & $0.37(0.78)$ & $0.36(0.76)$ & $0.38(0.8)$ & 0.232 \\
\hline Number of elderly people in the household & $0.81(0.75)$ & $0.9(0.72)$ & $0.71(0.77)$ & $-3.372^{* * *}$ \\
\hline
\end{tabular}


Table 6 Detailed summary statistics for multiple-sibling migrants (Continued)

\begin{tabular}{|c|c|c|c|c|}
\hline Household size & $4.28(2.23)$ & $4.49(2.1)$ & $4.07(2.33)$ & $-2.477^{* *}$ \\
\hline $\begin{array}{l}=1 \text { if non-sibling migrant present; } \\
=0 \text { otherwise }\end{array}$ & $0.14(0.35)$ & $0.09(0.29)$ & $0.19(0.39)$ & $3.830 * * *$ \\
\hline $\begin{array}{l}=1 \text { if the household owns land and/or house; } \\
=0 \text { otherwise }\end{array}$ & $0.90(0.29)$ & $0.92(0.27)$ & $0.89(0.32)$ & $-1.597^{*}$ \\
\hline N & 700 & 347 & 353 & \\
\hline
\end{tabular}

Notes to the table: (i) The fifth column contains $t$ tests/z-scores for the difference in means/proportions between non-remitters and remitters. (ii) Standard deviations are reported in parentheses. (iii) ****, and *** represent the statistical significance of the differences for the 10,5 , and $1 \%$ significance levels, respectively. (iv) The $x^{2}$ tests are testing for differences between non-remitters and remitters for categorical variables. (v) Not all the variables featured in the preliminary analysis are included here. We only employ those variables found to have a significant effect on either the probability of remitting or the amount of remittances sent by multiple migrants 
Table 7 The probability of remitting and the volume of remittances (control variables)

\begin{tabular}{|c|c|c|}
\hline Variables & Probability of remitting & Remittance level \\
\hline \multirow[t]{2}{*}{$=1$ if employed } & $0.415^{* * *}$ & $49,555^{* * *}$ \\
\hline & $(0.0298)$ & $(12,471)$ \\
\hline \multirow[t]{2}{*}{$=1$ if self-employed } & $0.268^{* * *}$ & $24,387^{*}$ \\
\hline & $(0.0563)$ & $(14,351)$ \\
\hline \multirow[t]{2}{*}{$=1$ if lives with relatives and/or friends } & $-0.0829^{* *}$ & 21,568 \\
\hline & $(0.0388)$ & $(22,115)$ \\
\hline \multirow[t]{2}{*}{$=1$ if migration length is 1 to 3 years } & $0.0213^{* *}$ & $9515^{* * *}$ \\
\hline & $(0.00968)$ & $(3314)$ \\
\hline \multirow[t]{2}{*}{$=1$ if receives transfers from the household of origin } & $-0.186^{* * *}$ & -9110 \\
\hline & $(0.0433)$ & $(16,186)$ \\
\hline \multirow[t]{2}{*}{$=1$ if located in external destination } & 0.0335 & $79,129^{* * *}$ \\
\hline & $(0.0324)$ & $(13,914)$ \\
\hline \multirow[t]{2}{*}{$=1$ if the head is unemployed } & $-0.100^{*}$ & $-12,951$ \\
\hline & $(0.0543)$ & $(34,623)$ \\
\hline \multirow[t]{2}{*}{ Proportion of children in the household of origin } & $-0.357^{* * *}$ & $-63,352$ \\
\hline & $(0.137)$ & $(38,669)$ \\
\hline \multirow[t]{2}{*}{$=1$ if head is male ${ }^{\dagger}$} & $-0.0776^{*}$ & \\
\hline & $(0.0351)$ & \\
\hline \multirow[t]{2}{*}{ Size of the household of origin ${ }^{\dagger}$} & $0.0321^{* * *}$ & \\
\hline & $(0.0087)$ & \\
\hline \multirow[t]{2}{*}{ Birth rank } & $-0.0437^{* * *}$ & -724 \\
\hline & $(0.0105)$ & $(4467)$ \\
\hline N & 1092 & 542 \\
\hline$R$-squared & & 0.235 \\
\hline Pseudo $R$-squared & 0.324 & \\
\hline
\end{tabular}

Notes to the table: (i) ${ }^{*} * *$, and ${ }^{* *}$ denote statistical significance from zero at the 10,5 , and $1 \%$ levels, respectively using two-tailed tests. (ii) Robust standard errors clustered by the household are reported in parentheses. (iii) ${ }^{\dagger}$ These variables are not included in the OLS regression model to prevent over-parameterizing the model. The variables were originally used as identification variables in the Heckman selection model and were found to have statistically insignificant effects on the level of remittances sent. (iv) Other variables are included in these models but not shown here in order to conserve space (see text for details)

\section{Competing interests}

The IZA Journal of Migration is committed to the IZA Guiding Principles of Research Integrity. The author declares that she has observed these principles.

\section{Acknowledgements}

The author would like to thank Barry Reilly, and an anonymous referee, for providing constructive comments on an earlier draft of this paper.

Responsible editor: Denis Fougère

Received: 19 January 2016 Accepted: 28 March 2016

Published online: 10 June 2016

\section{References}

Agarwal R, Horowitz AW. Are international remittances altruism or insurance? Evidence from Guyana using multiplemigrant households. World Dev. 2002;30(11):2033-44.

Agesa RU, Kim S. Rural to urban migration as a household decision: evidence from Kenya. Rev Dev Econ. 2001;5(1):60-75. Amuedo-Dorantes C, Pozo S. Remittances as insurance: evidence from Mexican immigrants. J Popul Econ. 2006;19(2):227-54. Antman FM. Elderly care and intrafamily resource allocation when children migrate. J Hum Resour. 2012:47(2):331-63. Batista C, Umblijs J. Do migrants send remittances as a way of self-insurance? Oxf Econ Pap. 2016;68(1):108-30. 
Batista C, Silverman D, Yang D. Directed giving: evidence from an inter-household transfer experiment. J Econ Behav Organ. 2015;118:2-21.

Bernheim BD, Andrei S, Summers LH. The strategic bequest motive. J Polit Econ. 1985;93(6):1045.

Bett $\sqcup$. The effect of diaspora remittances on economic growth in Kenya: Nairobi, Kenya; University of Nairobi. 2013.

Binzel C, Fehr D. Giving and sorting among friends: evidence from a lab-in-the-field experiment. Econ Lett. 2013;121:214-7.

Black R, King R. Editorial introduction: migration, return and development in West Africa. Popul Space Place. 2004;10(2):75-83.

Bound J, Jaeger DA, Baker RM. Problems with instrumental variables estimation when the correlation between the instruments and the endogenous explanatory variable is weak. J Am Stat Assoc. 1995;90(430):443-50.

Brown RPC. Estimating remittance functions for Pacific Island migrants. World Dev. 1997;25(4):613-26.

Brown RPC, Connell J. Occupation-specific analysis of migration and remittance behaviour: Pacific Island nurses in Australia and New Zealand. Asia Pacific Viewpoint. 2006;47(1):135-50.

Carling J. The determinants of migrant remittances. Oxf Rev Econ Policy. 2008;24(3):581-98.

Clemens M. Do Visas Kill? Health effects of African health professional emigration. Center for Global Development Working Paper. 2007, (114).

Cox D. Motives for private income transfers. J Polit Econ. 1987;95(3):508-46.

Cox D, \& Rank MR (1992). Inter-Vivos Transfers and Intergenerational Exchange. The Review of Economics and Statistics, 74(2), 305-314.

Cox D, Eser Z, Jimenez E. Motives for private transfers over the life cycle: an analytical framework and evidence for Peru. J Dev Econ. 1998:55(1):57-80.

De Arcangelis G, Joxhe M, McKenzie D, Tiongson E, Yang D. Directing remittances to education with soft and hard commitments: evidence from a lab-in-the-field experiment and new product take-up among Filipino migrants in Rome. J Econ Behav Organ. 2015;111:197-208.

De la Brière B, Elisabeth S, De Alain J, Sylvie L. The roles of destination, gender, and household composition in explaining remittances: an analysis for the Dominican Sierra. J Dev Econ. 2002;68(2):309-28.

Funkhouser E. Remittances from international migration: a comparison of El Salvador and Nicaragua. Rev Econ Stat. 1995;77(1):137-46

Gubert F. Do migrants insure those who stay behind? Evidence from the Kayes area (Western Mali). Oxf Dev Stud. 2002;30(3):267-87.

Heckman JJ. Sample selection bias as a specification error. Econometrica. 1979;47(1): 153-61.

Hoddinott J. A model of migration and remittances applied to Western Kenya. Oxf Econ Pap. 1994;46(3):459-76.

Hoddinott J. Modelling remittance flows in Kenya. J Afr Econ. 1992;1 (2):206-32.

Jack W, Suri T. Mobile money: the economics of M-Pesa. Natl Bur Econ Res. 2011.

Johnson GE, Whitelaw WE. Urban-rural income transfers in Kenya: an estimated-remittances function. Econ Dev Cult Chang. 1974;22(3):473-9.

Kanyangoga JB. Integrating migration with development in EAC: policy challenges and recommendations. CUTS Geneva Resource Centre: Geneva, Switzerland; (2010).

Knowles JC, Anker R. An analysis of income transfers in a developing country: the case of Kenya. J Dev Econ. 1981;8(2):205-26.

Lin T-F, Schmidt P. A test of the Tobit specification against an alternative suggested by Cragg. Rev Econ Stat. 1984;66:174-7.

Liu Q, Reilly B. Income transfers of Chinese rural migrants: some empirical evidence from Jinan. Appl Econ. 2004;36(12): 1295-313.

Lucas REB, Stark O. Motivations to remit: evidence from Botswana. J Polit Econ. 1985;93(5):901-18.

Manski Charles F. Identification of endogenous social effects: the reflection problem. Rev Econ Stud. 1993;60(3):531-42.

Markova E, Reilly B. Bulgarian migrant remittances and legal status: some micro-level evidence from Madrid. SouthEastern Eur J Econ. 2007:5(1):55-69.

Mas I, Radcliffe D. Scaling mobile money. J Payments Strat Syst. 2011;5(3):298-315.

Mikusheva A, Poi BP. Tests and confidence sets with correct size when instruments are potentially weak. Stata J. 2006; 6(3):335-47.

Moreira MJ, Poi BP. Implementing conditional tests with correct size in the simultaneous equations model. Stata Journal. 2003;1(1):1-5.

Mukras MS, Oucho JO, Bamberger M. Resource mobilization and the household economy in Kenya. Can J Afr Stud. 1985;19(2): 409-21.

National Council for Population and Development (NCPD). 2011. http://ncpd-ke.org/. Accessed in March 2016.

Naufal GS. Why remit? The case of Nicaragua. IZA Discussion Papers. 2008.

Piotrowski M. Sibling influences on migrant remittances, evidence from Nang Rong, Thailand. J Popul Ageing 2008;1(2-4):193-224.

Plaza S, Navarrete M, Dilip R. Migration and remittances household surveys in Sub-Saharan Africa-methodological aspects and main findings. World Bank, Washington, DC. 2011.

Rosenzweig MR, Stark O. Consumption smoothing, migration, and marriage: evidence from rural India. J Polit Econ. 1989;97(4):905-26.

Staiger DO, Stock JH. Instrumental variables regression with weak instruments. National Bureau of Economic Research Cambridge, Massachusetts, USA, 1994.

Stark O, Lucas REB. Migration, remittances, and the family. Econ Dev Cult Chang. 1988;36(3):465-81. 254.

Torero M, Viceisza A. To remit, or not to remit: that is the question. A remittance field experiment. J Econ Behav Organ. 2015;112:221-36.

Wooldridge JM. Econometric analysis of cross section and panel data: Cambridge, Massachusetts and London, England; MIT press. 2010

World Bank. Migration and Remittances Factbook 2011. edited by World Bank. Second ed. Washington DC: World Bank 2011. doi: 10.1596/978-0-8213-8218-9.

World Bank, Global economic prospects. Economic implications of remittances and migration. 2006. 